\title{
The Effects of Group Structure, Social Skills and Interaction Frequency on Task Performance in Computer Supported Collaborative Learning*
}

\author{
Erkan Çalışkan ** \\ Deniz Deryakulu***
}

\begin{abstract}
The purpose of this study was to examine the effects of group structure, levels of social skills and interaction frequency on students' individual and group task performance in computer supported collaborative learning. There were three types of groups: girls, boys and mixed. Participants were 54 elementary $7^{\text {th }}$ and $8^{\text {th }}$ grade students. In the data gathering phase, students' individual and group reports, records of CSCL tools such as chat, e-mail and forum, and Social Skills Scale were used. In the data analysis phase, one-way ANOVA, independent sample t-test, bivariate and partial correlation, Kruskal Wallis analysis, and multiple linear regression analysis were applied. Results showed that group structure didn't affect students' individual or group task performance in computer supported collaborative learning. Interaction frequency, on the other hand, predicted students' individual task performance whereas social skills did not.
\end{abstract}

Keywords: Computer supported collaborative learning, group structure, social skills, interaction frequency.

\footnotetext{
* This study was based on a master thesis conducted under the supervision of the second author and submitted by the first author to the Ankara University, Graduate School of Educational Sciences.

${ }_{* * *}^{* *}$ Computer Teacher.

Assist. Prof. Dr. Ankara University, Faculty of Educational Sciences. deryakul@education.ankara.edu.tr
} 


\section{SUMMARY}

Introduction: Collaboration refers to the fact that a group of people work together on a task. In a collaborative learning process, two or more people are required to learn something together, what has to be learned can only be accomplished if the group works in collaboration (Gros, 2001). Dillenbourg (1999, as cited in Gros, 2001) defines a situation as collaborative if peers are (a) more or less at the same level and can perform the same action, (b) have a common goal, and (c) work together. Computer Supported Collaborative Learning (CSCL) refers to computerized systems or environments that encourage learning in collaboration by facilitating needed communication, negotiation and social interaction among group members. The idea behind CSCL is that the use of computers can constitute a particularly valuable context for social interaction. Both synchronous and asynchronous tools such as e-mail, forum and chat sites can be used as a way to support communication and social interaction among group members in CSCL settings. On the other hand, according to group composition theory, many factors affect the productivity of collaborative groups. Group size and level of group homogeneity (Sharda et al., 2004), gender (Whitelock \& Scanlon, 1998) and social skills of group members (Cho et al., 2005), and social interaction (Kreijns, Kirschner, \& Jochems, 2003) are especially important for CSCL. On the other hand, researches have revealed mixed results about the effects of above mentioned variables on students' performance in CSCL environments. Therefore, the main purpose of this study was to examine the effects of group structure, social skill levels and interaction frequency on students' individual and group task performance in CSCL.

Method :Participants of this study were 54 elementary $7^{\text {th }}$ and $8^{\text {th }}$ grade students ( 27 boys and 27 girls). The dependent variable of study was task performance in CSCL activities (both individual and group). The independent variables of study were group structure, levels of social skills and interaction frequency in CSCL activities. In the data gathering phase, students' individual and group reports, records of CSCL tools such as chat, e-mail and forum, and Social Skills Scale were used. In the data analysis phase, one-way ANOVA, independent sample t-test, bivariate and partial correlation, Kruskal Wallis analysis, and multiple linear regression analysis were applied.

Results : The one-way ANOVA results showed that the group structure didn't affect students' individual or group task performance in computer supported collaborative learning activities. In other words, being and studying in single sex groups or mixed sex groups didn't affect students' 
individual or group task performance. The results of multiple linear regression analysis showed that interaction frequency was statistically significant predictor of students' individual task performance whereas level of social skills was not. In addition, it is found that the most frequently used CSCL tools by students were chat (46\%) and e-mail (26\%) while message boards (17\%) and forum (11\%) were less frequently used by students.

Conclusions :This study demonstrated that the group structure which composed based on students' gender had no significant impact on students' individual or group task performance in CSCL settings. However, these results may be due to the age or cultural background of the participants. Therefore, future studies should address these issues in cultural and developmental context. This study also concentrated on the potential benefits of students' levels of social skills and interaction frequencies in CSCL settings. Interaction frequency was found as the significant predictor of students' individual task performance whereas levels of social skills had no positive impact on both individual and group task performance. This result would stem from the nature of Social Skills Scale used in this study which is designed to measure children's social skills mostly in face-to-face settings. Therefore, there is a need to develop new instruments to measure individuals' social behaviors and skills in computer-mediated (online) communication settings. 


\title{
Bilgisayar Destekli Ortaklaşa Öğrenmede Grup Yapısı, Sosyal Beceri ve Etkileşim Sıklığının Görev Başarısına Etkisi* $^{*}$
}

\author{
Erkan Çalışkan** \\ Deniz Deryakulu**
}

ÖZ: $\mathrm{Bu}$ araştırmanın amacı, grup yapısının (kız, erkek ya da karma gruplarda çalışmanın), sosyal beceri düzeyinin ve etkileşim sıklığının öğrencilerin bilgisayar destekli ortaklaşa öğrenme etkinliklerindeki bireysel ve grup görev başarıları üzerindeki etkilerini incelemektir. Tek faktörlü gruplar arası deneysel desendeki çalışma, ilköğretim 7. ve 8. sınıf öğrencisi 54 öğrenci üzerinde yürütülmüştür. Veriler, öğrencilerin bireysel ve grup raporları, e-posta, sohbet, forum gibi BDOÖ araçlarının kayıtları ve Sosyal Beceri Ölçeği ile toplanmıştır. Verilerin çözümlenmesinde tek faktörlü ANOVA, ilişkisiz t-testi, ikili ve kısmi korelasyon, Kruskal Wallis testi ve çoklu doğrusal regresyon analizi kullanılmıştır. Sonuçlar, grup yapısına göre öğrencilerin bireysel ya da grup görev başarılarının anlamlı biçimde farklılaşmadığını; etkileşim sıklığının öğrencilerin bireysel görev başarılarının anlamlı bir yordayıcısı olduğunu; sosyal beceri düzeyinin ise, anlamlı bir yordayıcı olmadığını göstermiştir.

Anahtar Sözcükler: Bilgisayar destekli ortaklaşa öğrenme, grup yapısı, sosyal beceri, etkileşim sıklı̆̆ı.

\footnotetext{
* Bu çalışma Erkan Çalışkan'ın Yrd. Doç. Dr. Deniz Deryakulu yönetiminde tamamladığ 1 "Bilgisayar Destekli Ortaklaşa Öğrenmede Grup Yapısının Öğrencilerin Görev Başarısı Üzerindeki Etkisi” adlı yüksek lisans tezinin özetidir.

${ }^{* * *}$ Bilgisayar Öğretmeni.

*** Yrd. Doç. Dr. Ankara Üniversitesi, Eğitim Bilimleri Fakültesi. deryakul@education.ankara.edu.tr
} 


\section{GİRIŞ}

Bilgisayar destekli ortaklaşa öğrenme (BDOÖ) etkinlikleri, öğrencilerin bir öğrenme görevini aynı ya da farklı yer ve zamanlarda bilgisayarların internet tabanlı araçlarını kullanarak ortak bir çalışmayla yerine getirdikleri etkinlikler olarak tanımlanabilir. Bilgisayar destekli ortaklaşa öğrenme, bilgiyi paylaşma ve üretmede sosyal-bilişsel süreçlerin bilgisayarlarla desteklenebileceği bir öğrenme ortamı oluşturma düşüncesi üzerine kuruludur. Bu ortamlar, bilgisayar destekli iletişim olanaklarıyla bireylerin aynı veya farklı yerlerden bir göreve katılarak birlikte çalışmalarına izin vermektedir (Komis, Avouris ve Fidas, 2002). Bu nedenle, BDOÖ, yoğun sosyal etkileşim süreçleriyle gerçekleşen ortak bilgi yapılandırılmasına dayalı öğrenme olarak betimlenmektedir (Brown ve Hartley, 1999; Hoadley ve Pea, 2001; Scardamalia ve Bereite, 1996). BDOÖ'nin temel öğeleri; mekân, zaman, öğrenme görevi, öğrenme ortamı ve öğrenme stratejisidir. BDOÖ'nin temel öğeleri incelendiğinde, internetin bu tür uygulamalar için oldukça uygun olduğu görülmektedir. Özellikle, internet üzerinden gerçekleştirilen elektronik ortaklıklar BDOÖ etkinliklerinin daha başarılı sonuçlar ortaya koymasını sağlayabilmektedir. Elektronik ortaklık, bireylerin, internet üzerinden sohbet, e-posta ve forum gibi araçları kullanarak ya da doğrudan internet üzerindeki sitelere ulaşarak diğer bireylerle bir amaç/görev doğrultusunda ortaklaşa çalışmalar yapmalarını kapsamaktadır (Frederick ve diğerleri, 1999; Gros, 2001). Elektronik ortaklık, internet üzerinden eş-zamanlı ya da eş-zamansız olarak gerçekleştirilebilmektedir.

Wegerif (1998), eş-zamanlı ve eş-zamansız öğrenme ağlarının etkili olmasında sosyal boyutun çok önemli olduğunu ve derslerin ya da öğrenme görevlerinin tasarımında sosyal etkileşimin özellikle dikkate alınması gerektiğini söylemektedir. BDOÖ gibi grup (takım) çalışmasına dayalı öğrenme etkinlikleri açısından sosyal kimlik, sosyal beceriler ve grup yapıları anahtar kavramlardır (Lea, Rogers ve Postmes, 2002). Öğrencilerin işbirliği yaptıkları ya da ortaklaşa çalıştıkları öğrenme ortamlarında sosyal etkileşime girme düzeyleri arttıkça öğrenme düzeylerinin de arttığ bilinmektedir (Northrup, 2001). Örneğin, BDOÖ ortamlarında öğrencilerin görev başarılarında gruplarda yaşanan sosyal etkileşimin oldukça önemli etkileri olduğu saptanmıştır (Kreijins, Kirschner ve Jochems, 2002). Bir diğer ifadeyle, öğrencilerin küçük gruplar içinde ortaklaşa çalıştıkları ortamlarda öğrenme performansıyla sosyal performans birbiriyle oldukça yakından ilişkilidir. Jehng (1997), öğrenme etkinliklerinde öğrenciler

arasındaki sosyal etkileşimin önemine dikkat çekmekte ve olumlu sosyal etkileşim için öğrencilerin belirli sosyal becerilere sahip olmalarının 
gerekliliğine vurgu yapmaktadır. Sosyal beceri kavramı "kișilerarası beceri" ya da "iletişim yeterliğì" olarak da anılmaktadır (Çakıl, 1998). Shepherd (1983; Akt. Altınoğlu-Dikmeer, 1997), sosyal beceriyi, "bireylerin sosyal etkileşimleri sırasındaki gözlenebilir davranışları" olarak tanımlamıştır. Bireylerin BDOÖ etkinliklerinde sosyal etkileşime girme düzeylerini etkileyebilecek değişkenlerden biri de cinsiyetleridir. Ancak, alanyazındaki araştırmalarda cinsiyet değişkeni ile ilgili çelişkili sonuçlara rastlanmaktadır. Örneğin Hartley (1999) tarafından yapılan bir araştırmada, kızların BDOÖ görevlerinde daha başarılı oldukları bulunmuştur. Ancak, Whitelock, Scanlon ve Taylor'n (1996; Akt. Whitelock ve Scanlon, 1998) yaptığ 1 araştırmada bilişsel süreçler açısından cinsiyet grupları arasında anlamlı farklılaşmalar olmadığı görülmüş̧ür. Benzer biçimde, beş yılı aşan bir süre boyunca 475 ilköğretim öğrencisi üzerinde gerçekleştirilen BDOÖ uygulamalarında iletişim sürecinde kızların erkeklere oranla daha olumlu zaman geçirdikleri, bununla birlikte, görev başarısı açısından kız ya da erkek öğrenciler arasında önemli farklılıklar olmadığı saptanmıştır (Bruckman, Jensen ve DeBonte, 2002).

Scott, Mandryk ve Inkpen (2003) tarafından yapılan bir çalışmada ise, yeni teknolojilerin kullanımının öğrenciler arasındaki ortaklaşa çalışmayı nasıl etkileyeceği araştırılmıştır. Araştırma kapsamında eş-zamanlı olarak yürütülen etkinliklerde 9 ile 11 yaşları arasındaki 40 öğrenciye bilgisayar destekli ortaklaşa öğrenme etkinlikleri yaptırılmıştır. Öğrenciler, erkek, kız ve karma olarak ve bir bilgisayara tek fare ya da iki fare takılı koşullar altında gruplara ayrılmıştır. Öğrenciler Kidpad adlı bir çizim programında kendilerine verilen yap-bozları çözmeye çalışmışlardır. Süreç boyunca öğrenci etkileşimleri kaydedilmiştir. Sonuçlar, bir bilgisayara bir farenin takılı olduğu gruplardaki çocukların ne yapacakları hakkında daha çok konuştuklarını ve yap-bozu daha çabuk çözebildiklerini göstermiştir. $\mathrm{Bu}$ durumun, iki farenin kullanıldığı gruplarda öğrencilerin birbirleriyle iletişime geçmeden bağımsız olarak çalışmalarından, tek fareli gruplarda ise öğrencilerin ne yapılacağına ilişkin sıkça görüş alış-verişi yapmalarından ve ortak verilen karara uygun hareket etmelerinden kaynaklandığ 1 düşünülmüştür. Cinsiyet açısından ise, kız grubunda etkileşim (yazılımdaki araç paylaşımı-fare paylaşımı-görüş paylaşımı) en yüksek iken, karma grup etkileşimi en az olan grup olarak gözlemlenmiştir. Bunun temel nedeni olarak da, öğrencilerin yaş özellikleri ve yüzyüze ortamda olmaları göz önüne alındığında kızların birbirleriyle iletişime geçmeye daha istekli olmaları ve karma gruplarda gözlemlenen cinsiyet çatışması olarak açıklanmıştır. 
Lipponen ve Hakkarainen (2001) tarafindan Finlandiya'da bir ilköğretim okulunda gerçekleştirilen ve iki yıl süren çalışmanın ilk yılında erkek öğrencilerin BDOÖ etkinliklerinde daha çok güdülendikleri bulunmuştur. Ancak, araştırmanın ikinci yılında öğretmenlerin erkek öğrencileri kontrol etmesi, okuma-yazma ve matematik gibi temel derslere önem verilmesiyle birlikte cinsiyetler arasındaki farklılığın ilk yılki kadar büyük olmadığı görülmüştür. Araştırmacılar, BDOÖ etkinliklerinde öğrencilere verilen öğrenme görevlerinin içeriğinin ve türünün öğrenme çıktılarını farklı biçimde etkileyebileceğini belirtmişlerdir.

BDOÖ gibi grup çalışmasını destekleyen yaklaşımların başarılı sonuçlar vermesinde grup liderliği ve grup içi iletişim oldukça önemli öğelerdir. Yamaguchi, Bos ve Olson (2002) tarafından yapılan bir araştırmada kız öğrencilerin grup liderliğine ilgisinin düşük olduğu, erkek öğrencilerin ise lider olma konusunda daha ilgili ve istekli oldukları görülmüş̧ür. Eagly ve Karau (1991) erkeklerin görev odaklı liderliğe eğilimli olduklarını, kızların ise ilişki odaklı liderliğe eğilimli olduklarını belirtmektedirler. Whitelock ve Scanlon (1998) tarafindan yürütülen bir araştırmada ise, kızlardan oluşan gruplardaki etkileşimin erkek ve karma gruplarından daha yoğun olduğu saptanmıştır. Araştırmalar topluca değerlendirildiğinde, BDOÖ gruplarında kızların erkeklerden daha fazla iletişime/etkileşime girdikleri, bununla birlikte, görev başarısı açısından cinsiyet faktörüne bağlı net ayrışmaların söz konusu olmadığı gözlemlenmektedir. Bu durum, BDOÖ gruplarında gerçekleşen etkileşimi ve görev başarısını etkileyebilecek farklı değişkenleri ele alan daha çok araştırmaya gereksinim olduğunu göstermektedir. Bu araştırmanın temel amac1, ilköğretim öğrencileri üzerinde yürütülen bilgisayar destekli ortaklaşa öğrenme etkinliklerinde grup yapısının, sosyal beceri düzeyinin ve etkileşim sıklığının öğrencilerin bireysel ve grup görev başarıları üzerindeki etkisini incelemektir.

\section{YÖNTEM}

\section{Model}

$\mathrm{Bu}$ araştırma, tek faktörlü gruplar arası deneysel desendedir. Araştırmanın bağımlı değişkeni görev başarısıdır. Görev başarısı, öğrencilerin bireysel ve grup olarak hazırladıkları proje raporlarının değerlendirilmesi sonucu elde edilen puanlarla belirlenmiştir. Araştırmanın bağımsız değişkenleri ise, grup yapısı, sosyal beceri düzeyi ve etkileşim sıklığıdır. Grup yapısı, gruplardaki öğrencilerin cinsiyetlerine bağlı olarak kız, erkek ve karma olmak üzere üç düzeydedir. Sosyal beceri düzeyi, öğrencilere uygulanan Sosyal Beceri Ölçeği'nden alınan puanlarla 
belirlenmiştir. Öğrencilerin BDOÖ etkinliklerinde kullandıkları e-posta, forum, mesaj tahtası ve sohbet araçlarını kullanma sıklığı ise etkileşim sıklığını göstermektedir.

\section{Çalışma Grubu}

Araştırmanın çalışma grubu, Ankara ili Altındağ ilçesi Ayşe Numan Konakçı İlköğretim Okulu, Çubuk İlçesi Atatürk İlköğretim Okulu ve Güdül ilçesi Güdül İlköğretim Okulu 7. ve 8. sınıf öğrencilerinden seçilen 27'si kız, 27 'si erkek toplam 54 öğrenciden oluşmaktadır. Çalışmada öğrenciler 4 kız, 4 erkek ve 4 karma olmak üzere 12 farklı grup altında toplanmıştır.

\section{Verilerin Toplanması}

İnternet Araçları: Araştırmada BDOÖ etkinlikleri hem eş-zamanlı hem de eş-zamansız internet araçları üzerinden yürütülmüştür. Araştırma kapsamında birinci araştırmacı tarafından hazırlanarak www.birlikteogrenelim.com adresinde yayınlanan web sitesindeki araçlar ve kulanım amaçları şöyledir;

Forum: Öğrencilerin eş-zamansız olarak gerçekleştirdikleri grup içi ve dış1 tartışmaların yürütüldüğü bölümdür.

Sohbet: Öğrencilerin eş-zamanlı olarak görüşme gerçekleştirmelerini sağlamak amacıyla hazırlanmıştır.

E-Posta: Öğrencilerin buldukları bilgi ve dosyaları birbirleriyle rahatça paylaşmalarına olanak verir.

Mesaj Panosu: Öğrencilerin birbirlerine mesaj bırakabildikleri ve görüşlerini bildirdikleri bölümdür.

Arama: Yapılacak araştırmalar için öğrencilerin internet üzerinden ulaşabilecekleri temel arama motorlarının adresleri bu kısımda bulunmaktadır.

Web sunucu, her bir öğrencinin site üzerinde gerçekleştirdiği işlemlerin kayıtlarını tutmuştur. Böylece öğrencilerin sürece katılım düzeyleri, bir diğer ifadeyle, etkileşim araçlarını kullanım sıklıkları belirlenmiştir.

Sosyal Beceri Ölçeği: Araştırmada öğrencilerin sosyal beceri düzeylerini belirlemek üzere Kocayörük (2000) tarafından geliştirilen Sosyal Beceri Ölçeği (SBÖ) kullanılmıştır. Ölçek, dörtlü Likert tipinde 20 maddeden oluşmaktadır. Ölçekten alınabilecek en yüksek puan 80 , en düşük puan ise 20 'dir. Ölçeğin yap1 geçerliğinin belirlenmesi için faktör analizi yapılmış, güvenilirliğinin belirlenmesi için ise Cronbach alfa iç-tutarlılık katsayısı hesaplanmıştır. Faktör analizi sonucunda ölçeğin tek faktörde 
toplandığı belirlenmiștir. Ölçeğin Cronbach alfa iç-tutarlılık katsayısı ise 0.75 olarak bulunmuştur. Bu çalışmada elde edilen veriler üzerinden kontrol amacıyla yapılan geçerlik güvenilirlik çözümlemelerine göre, ölçeğin tek faktörlü olarak kullanılabileceği ve Cronbach alfa iç-tutarlık katsayısının 0.79 olduğu belirlenmiştir.

\section{İşlem}

Daha önce de belirtildiği gibi, öğrenciler 4 kız, 4 erkek ve 4 karma olmak üzere 12 farklı grup altında toplanmıştır. Gruplar, iki ayrı ilköğretim okulundan ikişer öğrenci olmak üzere dörder öğrenciden oluşmaktadır. Gruplar oluşturulduktan sonra, öğrencilere deneysel işlemlerde kullanacakları kullanıcı adları ve şifreleri verilmiş, grup arkadaşları tanıştırılmış ve görevler dağıtılmıştır. On iki gruba dört farklı görev verilmiştir. Her üç tür gruba (kı, erkek ve karma) aynı görev verilmiş ve gruplar birbirinden bağımsız çalışmıştır. Verilen görevler şunlardır; Sigara ve Sigaranın Zararları, Beden Dili ve Bireyler Arası İletişime Etkileri, Küresel Isınma ve Türkiye’ye Etkisi, Meslek İncelemesi.

Birinci araştırmacı tarafından daha önceden bu görevlerle ilgili olarak internette taramalar yapılmış, görevlerle ilgili yeterli ve güvenilir kaynağa erişilebildiği kontrol edilmiştir. Öğrencilerin ulaşabilecekleri kaynaklar dikkate alınarak her bir görev için alt konular belirlenmiş ve bunlar öğrencilere site üzerinden duyurulmuştur. Öğrencilerden hazırlayacakları raporlarda bu alt konulara değinmeleri ve yine sitede verilen rapor hazırlama ölçütlerine göre rapor hazırlamaları istenmiştir. Öğrenciler altı hafta boyunca gruplar halinde kendilerine verilen görevlerle ilgili çalışmaları yaptıktan sonra hem bireysel, hem de grup olarak raporlar hazırlamışlardır. Hazırlanan bu raporlar birinci araştırmacı ve bir başka ilköğretim öğretmeni tarafından içerik (kapsam, doğruluk ve yapılandırma) ve biçim (öğrencilere daha önce sunulan rapor hazırlama ölçütleri) açısından ayrı ayrı değerlendirilmiştir. Her iki değerlendirmecinin verdiği puanların ortalaması alınarak öğrencilere hem bireysel hem de grup görev başarı puanı verilmiştir.

\section{BULGULAR VE YORUM}

Öğrencilerin BDOÖ etkinliklerindeki bireysel ve grup görev başarılarına ilişkin aritmetik ortalama ve standart sapma değerleri Tablo 1'de verilmiştir. Aritmetik ortalamalar incelendiğinde, hem bireysel, hem de grup olarak en yüksek görev başarısını karma gruplarda çalışan öğrencilerin gösterdiği görülmektedir. 
Tablo 1. Bireysel ve Grup Görev Başarısı Aritmetik Ortalama ve Standart Sapma Değerleri

\begin{tabular}{llllllll}
\hline \multicolumn{3}{c}{ Bireysel Görev Başarıs1 } & \multicolumn{5}{c}{ Grup Görev Başarıs1 } \\
\hline & $\mathrm{N}$ & $\overline{\mathrm{X}}$ & $\mathrm{S}$ & & $\mathrm{N}$ & $\overline{\mathrm{X}}$ & $\mathrm{S}$ \\
Karma & 18 & 51,94 & 24,02 & Karma & 4 & 76,25 & 26,26 \\
Kız & 18 & 39,17 & 18,49 & $\mathrm{~K} 1 \mathrm{z}$ & 4 & 33,75 & 24,28 \\
Erkek & 18 & 42,50 & 21,71 & Erkek & 4 & 52,50 & 30,14 \\
Toplam & 54 & 44,54 & 21,81 & Toplam & 12 & 54,17 & 30,44 \\
\hline
\end{tabular}

Öğrencilerin bireysel görev başarı puanları ile grup görev başarı puanlarının karşılaştırılması amacıyla ilişkisiz t-testi uygulanmıştır, sonuçlar Tablo 2'de verilmiştir.

Tablo 2. Bireysel ve Grup Görev Başarı Puanlarının Karşılaştırıldığı İlişkisiz T-Testi Sonuçları

\begin{tabular}{lllllll}
\hline Görev Başarıs1 & $\mathrm{N}$ & $\overline{\mathrm{X}}$ & $\mathrm{S}$ & $\mathrm{sd}$ & $\mathrm{t}$ & $\mathrm{p}$ \\
\hline Grup & 12 & 54,17 & 30,44 & 14,54 & 1,07 & .303 \\
Bireysel & 54 & 44,54 & 21,81 & & & \\
\hline
\end{tabular}

Öğrencilerin bireysel ve grup görev başarı puanları arasındaki fark anlamlı değildir. $\mathrm{Bu}$ bulgu, Gokhale'in (1995) üniversite öğrencileri üzerinde yaptığı deneysel çalışmanın bulguları ile benzerlik göstermektedir. Anılan çalışmada, öğrencilerin BDOÖ etkinlikleri sırasında ortaklaşa öğrenmeyi daha çok istemelerine karşın, başarı açısından ortaklaşa çalışanlar ve bireysel çalışanlar arasında istatistiksel olarak anlamlı bir fark saptanmamıştır. Lingnau, Hoppe ve Mannhaupt (2003) tarafından yaklaşık 400 ilköğretim öğrencisi üzerinde yapılan farklı bir çalışmada ise, öğrencilerin ortaklaşa öğrenme etkinliklerindeki bireysel başarılarının grup başarılarından daha yüksek olduğu bulunmuştur. Pek çok araştırmacı, BDOÖ etkinliklerinde bireysel başarının daha yüksek olarak bulunmasını, öğrencilerin yer ve zamana bağlı olmadan çalışma yapabilmelerine, iletişim özgürlüğü nedeniyle çoğunun süreçten memnun kalmalarına ve bilgisayarların genel olarak bireyleştirilmiş öğretimi desteklemesine bağlamaktadırlar (bkz. Edwards ve Clear, 2001; Tao ve Gunstone, 1999; Thomas ve Carswell, 2000). Ancak bu araştırmada, öğrencilerin bireysel 
görev başarısı ile grup görev başarısı arasında anlamlı bir farklılaşma bulunmamıştır. Anımsanacağı gibi, bireysel görev başarı puanları her öğrenci tarafindan bireysel olarak hazırlanan raporlara dayalı olarak hesaplanmıştı. Öte yandan, tüm öğrenciler süreç içerisinde grup olarak çalıştıkları için bireysel raporlar grup tartışmaları ve grup raporlarından etkilenmiş olabilir. $\mathrm{Bu}$ nedenle de, öğrencilerin bireysel ve grup görev başarıları arasında istatistiksel yönden anlamlı farklılaşmalar ortaya çıkmamış olabilir.

Öğrencilerin bireysel ve grup görev başarılarının grup yapısına göre nasıl değiştiğinin belirlenmesi amacıyla, bireysel görev başarısı için tek faktörlü ANOVA, grup görev başarısı için ise Kruskal Wallis analizi uygulanmıştır. ANOVA sonuçlarına göre, grup yapısının bireysel görev başarıs1 üzerinde anlamlı bir etkisi olmadığ 1 görülmüştür $[F(2,51)=1.706$, $\mathrm{p}=.192]$. Benzer biçimde, Kruskal Wallis analizi sonuçları da öğrencilerin grup görev başarılarının grup yapısına göre anlamlı olarak farklılaşmadığını göstermiştir $\left[\mathrm{X}^{2}(2)=3.90, \mathrm{p}=.142\right]$. Özetle, öğrencilerin sadece kız, sadece erkek ya da karma gruplarda çalışmalarının ne bireysel, ne de grup görev başarılarını anlamlı olarak değiştirmediği söylenebilir. Alanyazındaki araştırmalarda da bu bulguya benzer sonuçlara rastlanmaktadır. Örneğin, Whitelock, Scanlon ve Taylor'ın (1996; Akt. Whitelock ve Scanlon, 1998) yetişkinler üzerinde yaptığı bir araştırmada bilişsel süreçler açısından cinsiyet grupları arasında anlamlı bir farklılığın olmadığı görülmüştür. Benzer biçimde, Bruckman, Jensen ve DeBonte (2002) tarafindan gerçekleştirilen bir çalışmada da BDOÖ etkinliklerinde kızların erkeklere oranla iletişim sürecinde daha olumlu zaman geçirmelerine karşın görev başarısı açısından kızlar ve erkekler arasında anlamlı bir fark görülmemiştir. Lea, Rogers ve Postmes (2002), sosyal kimliğin ve grup yapısının BDOÖ'deki etkileşimin ve süreç başarısının önemli etkileyicileri olduğunu belirtmektedirler, bununla birlikte, yaptıkları çalışmada bu öğeler açısından farklı cinsiyet grupları arasında anlamlı farklılaşmalar bulamamışlardır. Svensson ve Magnusson (2002) ise, BDOÖ gruplarında gruplar aras1 farklılı̆̆ın öğrencilerin cinsiyet dağılımı açısından nasıl bir grupta çalıştığına değil, öğrencilerin bireysel mi, yoksa ortaklaşa mı çalıştıklarına ve gruplarda aldıkları rollere bağlı olduğunu belirtmektedirler. Öte yandan, Hartley (1999) tarafından yapılan bir araştırmada ise, BDOÖ görevlerinde kızların erkeklerden daha başarılı olduğu görülmüştür. İleride yapılacak araştırmalarla denek sayısını arttırarak ve uzun süreli BDOÖ uygulamaları yaparak görev başarısında cinsiyet faktörüne bağlı tutarlı farklılaşmaların olup olmadığı daha ayrıntılı olarak incelenmelidir. 
Öğrencilerin sosyal beceri düzeylerinin ve etkileşim sıklığının bireysel görev başarı puanlarını nasıl etkilediğinin belirlenmesi için çoklu doğrusal regresyon analizi uygulanmıştır (bkz. Tablo 3). Öte yandan, grup görev başarı puanlarının normal dağılım göstermemesi nedeniyle sözü edilen değişkenlerle ilişkisinin incelenmesi için regresyon analizi kullanılamamış, grup görev başarısı ile sosyal beceri düzeyi ve etkileşim sıklığı puanları arasında hesaplanan korelasyon değerleri ise istatistiksel açıdan anlamsız olduğu için bu değerler yorumlanmamıştır.

Tablo 3. Bireysel Görev Başarısının Açıklanmasına İlişkin Çoklu Regresyon Analizi Sonuçları

\begin{tabular}{llllllll}
\hline Değişken & $\mathrm{B}$ & $\begin{array}{l}\text { Standart } \\
\text { Hata }\end{array}$ & $\beta$ & $\mathrm{t}$ & $\mathrm{p}$ & İkili r & Kısmi r \\
\hline Sabit & 16,171 & 15,658 & - & 1,033 &, 307 & - & - \\
$\begin{array}{l}\text { Sosyal Beceri } \\
\begin{array}{l}\text { Etkileşim } \\
\text { Sıklı̆̆ }\end{array}\end{array}$ & 0,053 & 0,231 & 0,017 & 0,231 &, 818 & $-0,318$ & 0,032 \\
\hline
\end{tabular}

$\mathrm{R}=0.874, \quad \mathrm{R}^{2}=0.763 \quad \mathrm{~F}_{(2-51)}=82.158, \quad \mathrm{p}=.000$

Bağımlı değişken (bireysel başarı) ile bağımsız değişkenler (sosyal beceri ve etkileşim sıklığı) arasındaki ikili ve kısmi korelasyonlar incelendiğinde, etkileşim sıklığı ile bireysel başarı arasında pozitif ve yüksek düzeyde bir ilişkinin ( $\mathrm{r}=0.87)$ olduğu ve diğer değişken kontrol altına alınsa bile bu ilişkinin $(r=0.86)$ devam ettiği görülmektedir. Sosyal beceri ile bireysel başarı arasında hesaplanan negatif ve düşük düzeydeki ikili korelasyonun $(\mathrm{r}=-0.32)$ ise diğer değişken kontrol edildiğinde, pozitif ancak çok düşük düzeyde $(\mathrm{r}=0.03)$ olduğu görülmektedir. Öte yandan, etkileşim sıklığı ve sosyal beceri bireysel başarı ile yüksek düzeyde anlamlı bir ilişki vermektedir $\left(\mathrm{R}=0.87, \mathrm{R}^{2}=0.76, \mathrm{~F}(2,51)=82.16, \mathrm{p}=.000\right)$. Anılan bu iki değişken, bireysel görev başarısındaki toplam varyansın yaklaşık \%76'sını açıklamaktadır.

Standardize edilmiş regresyon katsayısına $(\beta)$ göre, yordayıcı değişkenlerden etkileşim sıklığ bireysel görev başarısı üzerinde daha fazla öneme sahiptir. Regresyon katsayılarının anlamlılığına ilişkin t-testi sonuçları incelendiğinde, etkileşim sıklığı değişkeninin bireysel görev başarısı üzerinde anlamlı bir etkiye sahip olduğu, sosyal becerinin ise anlamlı bir etkiye sahip olmadığı görülmektedir. Bu bulgu, öğrencilerin bireysel görev başarılarının BDOÖ etkinliklerini yerine getirirken ortaya koydukları etkileşim sıklığına bağlı olduğunu, bir diğer söyleyişle, internet üzerindeki etkileşim araçlarını ne kadar sık kullanırlarsa, bireysel görev 
başarılarının o kadar yükseldiğini göstermektedir. Ancak, hemen belirtmek gerekir ki, etkileşim araçlarını kullanma sıklığı nicel bir göstergedir. İleride gerçekleştirilecek araştırmalarla, BDOÖ süreçlerindeki etkileşimin niteliği ile görev başarısı arasındaki ilişki incelenmelidir. Özellikle, bu süreçte gerçekleştirilen her türlü etkileşimin/iletişimin içeriğinin niteliksel çözümlemesi yapılarak etkileşimin sıklığının (niceliğinin) m1, yoksa içeriğinin (niteliğinin) mi daha belirleyici (önemli) olduğu konusu açıklığa kavuşturulmalıdır.

Öte yandan, öğrencilerin sosyal beceri düzeyinin BDOÖ etkinliklerindeki bireysel görev başarısının anlamlı bir yordayıcısı olmaması, araştırmada kullanılan Sosyal Beceri Ölçeğinin günlük yaşamda yüzyüze ortamlarda gösterilen sosyal davranışları ölçmek üzere hazırlanmış bir ölçek olmasından kaynaklanabilir. Ölçeğin bu özelliği nedeniyle, internet üzerinden gerçekleştirilen BDOÖ etkinliklerdeki bireysel görev başarısı ile sosyal beceri düzeyi arasında anlamlı bir ilişki ortaya çıkmamış olabilir. İleride, internet üzerindeki sosyal etkileşimler sırasında gösterilen sosyal davranışları/becerileri ölçmeye yönelik ölçme araçlarının geliştirilmesiyle bu konuda daha geçerli ve güvenilir bilgilere ulaşılabilecektir.

Araştırmada uygulanan deneysel işlemler dışında bağımlı değişken üzerinde etkisi olabilecek sosyal beceri düzeyi ve etkileşim sıklı̆̆ının deney grupları açısından farklılık gösterip göstermediğinin ortaya konması amacıyla tek faktörlü ANOVA yapılmıştır. $\mathrm{Bu}$ analize ilişkin betimsel bulgular Tablo 4'de verilmiştir.

Tablo 4. Grup Yapısına Göre Sosyal Beceri Düzeyi ve Etkileşim Sıklığı Puanları

\begin{tabular}{llllll}
\hline Grup Yapısı & \multicolumn{3}{c}{ Sosyal Beceri Düzeyi } & \multicolumn{2}{c}{ Etkileşim Sıklı̆̆ } \\
\hline \multirow{2}{*}{ Karma } & $\mathrm{N}$ & $\overline{\mathrm{X}}$ & $\mathrm{S}$ & $\overline{\mathrm{X}}$ & $\mathrm{S}$ \\
Kiz & 18 & 62,94 & 6,40 & 10,67 & 6,79 \\
Erkek & 18 & 66,06 & 8,05 & 7,83 & 6,06 \\
Toplam & 18 & 61,89 & 5,98 & 8,11 & 7,54 \\
\hline
\end{tabular}

Varyans analizi sonuçları incelendiğinde, sosyal beceri düzeyi $[F(2,51)=1.791, p=.177] \quad$ ve etkileşim siklığ $\quad[F(2,51)=.943, p=.396]$ açısından deney grupları arasında anlamlı bir farklılık olmadığı görülmüştür. Öte yandan, sosyal beceri düzeyi ve etkileşim sıklı̆̆ının grup görev başarısını nasıl etkilediğinin belirlenmesi amacıyla grup görev başarısı 
puanlarının normal dağılım göstermemesi nedeniyle regresyon analizi yapılmamış, sadece ikili ve kısmi korelasyonlar dikkate alınmıştır. Bu nedenle, sosyal beceri düzeyi ve etkileşim sıklığının grup görev başarısını yordayıp yordamadığını söyleyebilmek bu araştırmanın sınırlılıkları dikkate alındığında olanaklı değildir. İleride yapılacak araştırmalarda daha çok grupla çalışarak anılan değişkenlerin öğrencilerin grup görev başarılarının anlamlı birer yordayıcısı olup olmadıkları belirlenebilir.

Genel olarak değerlendirildiğinde, öğrencilerin BDOÖ etkinliklerindeki bireysel görev başarılarının, çalışırken ortaya koydukları etkileşim sıklığına bağlı olduğu bulunmuştur. Bir diğer söyleyişle, öğrenciler etkileşim araçlarını ne kadar sık kullanırlarsa ve sürece ne kadar fazla katılırlarsa, bireysel olarak o kadar başarılı olmuşlardır. Alanyazındaki çalışmalarda da ortaya konan sonuçlar, katılımcıların ortaklaşa görevlere ne kadar sık katılırlarsa bireysel gelişimlerinin o kadar üst düzeyde olduğu yönündedir (Barros ve Verdejo, 2000; Kim ve Bonk, 2002; Northrup, 2001; Stahl, 2003). Ortaklaşa öğrenme, öğrencilerin bireysel görüş ve bakış açıları ile ortak çoklu bakış açılarının paylaşımı, yeni bilişsel yapılar oluşturmak üzere önce kavramsal çelişkilere düşme ve daha sonra karşıllklı görüşmeler yaparak bunları giderme ile destekleneceğinden, bu tür etkinliklerde öğrenciler arası iletişim ve etkileşim oldukça önemlidir (Komis, Avouris ve Fidas, 2002).

Öte yandan, Anderson ve Kanuka (1997) tarafindan yapılan bir araştırmada deneklerin büyük çoğunluğunun BDOÖ araçlarını kullanarak doyurucu sosyal etkileşimi sağlayamadıkları için süreçten kendilerini geri çektikleri bulunmuştur. Bilgisayar ortamında oluşturulan sosyal bağlamların gerçek yüzyüze sosyal bağlamlardan oldukça farklı olması bu duruma neden olmuş olabilir. Bu çalışmada da sosyal beceri düzeyinin BDOÖ'de bireysel görev başarısı üzerinde etkili bir değişken olarak bulunmaması sözü edilen bilgisayar ortamındaki sosyal etkileşimin farklılığından kaynaklanmış olabilir.

Öğrencilerin BDOÖ etkinlikleri boyunca tutulan etkileşim kayıt sonuçlarına göre en fazla kullanılan araçlar sohbet (\%46) ve e-postadır (\%26). Bunları sirasiyla mesaj tahtası (\%17) ve forum (\%11) izlemektedir. Sohbetin en yaygın kullanılan araç olması, eş-zamanlı olarak çalışabilmesinden ve öğrencilerin böylece gerçek zamanlı olarak günlük yaşamdakine benzer etkileşime girebilmelerinden olabilir. Öte yandan, öğrenciler dosya alış verişi için ise en sık e-postayı kullanmışlardır. Motteram (2001) tarafından yapılan bir çalışmada da öğrencilerin çevrimiçi derslerde eş-zamanlı sohbeti ve genel görüşmelerde ise e-posta uygulamalarını daha çok kullandıkları saptanmıştır. Alanyazındaki araştırma 
sonuçlarına göre de sanal ve çevrimiçi öğrenme etkinliklerinde eş-zamansız uygulamaların yer ve zaman gibi sınırları daha etkin bir şekilde ortadan kaldırmasına karşın katılımcıların genel olarak eş-zamanlı görüşme araçlarını tercih ettikleri görülmüştür (Edwards ve Clear, 2001; Ellis, 1997; Hartley, 1999). İleride internet üzerinden yapılacak öğretim uygulamalarında öğrencilere sunulacak etkileşim araçlarına karar verilirken bu tür araştırma bulgularının dikkate alınmasında yarar vardır.

Son olarak belirtilmek gerekir ki, bu araştırmada öğrencilerin BDOÖ etkinliklerindeki görev başarılarının belirlenmesinde izlenen yaklaşım "öznelliği”" bakımından araştırmanın bir sinırlılı̆̆ 1 olarak değerlendirilmelidir. Daha önce de belirtildiği gibi, bu araştırmada öğrencilerin görev başarıları bireysel ve grup olarak hazırladıkları proje raporlarının iki ayrı değerlendirmeci tarafından puanlanması ile belirlenmişti. Değerlendirmede her ne kadar belirli ölçütler kullanılmış olsa da, tüm açık-uçlu araçların değerlendirilmesinde geçerli olan "öznellik" (subjectivity) tehlikesi bu değerlendirmeler için de geçerli olabilir. O nedenle, ileride BDOÖ ile ilgili çalışmalarda "öğrenci başarısı" ya da "görev başarısı" gibi değişkenlerin belirlenmesinde çoklu ölçme araç ve tekniklerinin (örneğin; çoktan seçmeli testler, ürün dosyaları, raporlar, iletişim/etkileşim kayıtları, gözlem, görüşme vb. gibi) bir arada kullanılması bir seçenek olarak düşünülmelidir.

\section{SONUÇ VE ÖNERILLER}

$\mathrm{Bu}$ araştırmada, bilgisayar destekli ortaklaşa öğrenme etkinliklerinde grup yapısının, sosyal beceri düzeyinin ve etkileşim sıklığının öğrencilerin bireysel ve grup görev başarıları üzerindeki etkisi incelenmiştir. Araştırmanın ortaya koyduğu sonuçlar, grup yapısının BDOÖ etkinliklerinde öğrencilerin bireysel ya da grup görev başarıları üzerinde anlamlı bir etkisi olmadığını göstermiştir. Bir diğer ifadeyle, öğrencilerin sadece kız, sadece erkek ya da karma gruplarda çalışmaları, bireysel ya da grup görev başarılarını anlamlı olarak farklılaştırmamıştır. İncelenen değişkenlerden yalnızca etkileşim sıklı̆̆ı öğrencilerin bireysel görev başarılarının anlamlı bir yordayıcısı olarak bulunmuştur. Buna göre, öğrenciler BDOÖ etkinlikleri sırasında internet tabanlı etkileşim araçlarını ne kadar çok kullanırlarsa bireysel görev başarıları da o düzeyde artmıştır. BDOÖ etkinlikleri sırasında öğrenciler internet üzerindeki etkileşim araçlarından en çok sohbeti ve dosya alışverişi için ise e-postayı tercih etmişlerdir. Öte yandan, sosyal beceri düzeyi ile öğrencilerin bireysel görev başarıları arasında anlamlı bir ilişki olmadığı görülmüştür. 
Öğretme-öğrenme süreçlerinde BDOÖ etkinlikleri koşullar göz önüne alınarak bireysel ya da grupla çalışılacak şekilde tasarımlanabilir. Eğer etkinlikler gruplar halinde olacaksa, gruplar oluşturulurken amaçlara göre farklı ya da tek cinsiyetten oluşan gruplar kullanılabilir. BDOÖ etkinliklerinin kullanılacağı uygulamalarda, üyeler arasındaki iletişimi arttırmak üzere internet tabanlı etkileşim araçlarının kullanımına yönelik çeşitli yönlendirmelerin yapılmasında yarar vardır. Ayrıca, bu uygulamalar sırasında öğrencilerin kendi isteklerine uygun ve esnek biçimde çalışabilmeleri için hem eş-zamansız hem de eş-zamanlı etkileşim araçlarına yer verilmelidir. Böylece, öğrencilerin hem bireysel, hem de grup olarak daha çok ve farklı türdeki kanallardan etkileşime girerek daha zengin öğrenme deneyimleri yaşayabilmelerine katkı sağlanabilir.

\section{KAYNAKLAR}

Altınoğlu-Dikmeer, D. İ. (1997). Sosyal Beceri Eğitiminin Sosyal İçedönük Ergenlerin İçedönüklük Düzeylerine Etkisi. Yayınlanmamış Yüksek Lisans Tezi, Ankara Üniversitesi, Sosyal Bilimler Enstitüsü, Ankara.

Anderson, T., \& Kanuka, H. (1997). On-line forums: New platforms for professional development and group collaboration. Journal of Computer Mediated Communication, 3(3). [Online]: http://www.ascusc.org/jcmc/vol3/issue3/anderson.html adresinden 5 Eylül 2004 tarihinde erişildi.

Barros, B., \& Verdejo, M. F. (2000). Analysing student interaction processes in order to improve collaboration. International Journal of Artificial Intelligence in Education, $11 . \quad$ [Online]: http://sensei.lsi.uned.es/ bbarros/papers/ijaied2000.pdf adresinden 6 Mart 2005 tarihinde erişildi.

Brown, E. C., \& Hartley, J. R. (1999). Effective pedagogies for managing collaborative learning in on-line learning environments. Educational Technology \& Society, 2(2), 39-57.

Bruckman, A., Jensen, C., \& DeBonte, A. (2002). Gender and programming achievement in a CSCL environment. CSCL 2002 Congress, Boulder, Colorado.

Cho, H., Gay, G., Davidson, B., \& Ingraffea, A. (2005). Social networks, communication styles, and learning performance in a CSCL community. Computers \& Education, [Online]:www.sciencedirect.com adresinden 18 Kasım 2005 tarihinde erişildi. 
Çakıl, N. (1998). Grupla Sosyal Beceri Ë̆itiminin Üniversite Öğrencilerinin Yalnızlık Düzeyleri Üzerindeki Etkisi. Yayınlanmamış Doktora Tezi, Hacettepe Üniversitesi, Sosyal Bilimler Enstitüsü, Ankara.

Dillenbourg, P. (Ed.). (1999). Collaborative learning: Cognitive and computational approaches. Amsterdam: Pergamon.

Eagly, A. H., \& Karau, S. J. (1991). Gender and the emergence of leaders: A meta-analysis. Journal of Personality and Social Psychology, 60(5), $685-710$.

Edwards, M. A., \& Clear, F. (2001). Supporting the collaborative learning of practical skills with computer-mediated communications technology. Educational Technology \& Society 4(1). [Online]: http://ifets.ieee.org/periodical/vol_1_2001/edwards.html adresinden 11 Aralık 2004 tarihinde erişildi.

Ellis, B. (1997, October). Virtual classroom technologies for distance education: The case for on-line synchronous delivery. North American Web Developers Conference, Alberta, Canada.

Frederick, A., Lillie, M., Gordon, L. P., Watt, D. L., \& Carter, R. (1999). Electronic collaboration: A practical guide for educators. The LAB at Brown University.

Gokhale, A. (1995). Collaborative learning enhances critical thinking. Journal of Technology Education, 7(1). [Online]: http://scholar.lib.vt.edu/ejournals/JTE/jte-v7n1/gokhale.jte-v7n1.html adresinden 20 Temmuz 2004 tarihinde erişildi.

Gros, B. (2001). Instructional design for computer-supported collaborative learning in primary and secondary school. Computers in Human Behavior, 17, 439-451.

Hartley, J. R. (1999). Effective pedagogies for managing collaborative learning in on-line learning environments. Educational Technology \& Society, 2(2). [Online]: http://ifets.ieee.org/periodical/vol_2_99/formal_ discussion_0399.html adresinden 19 Ekim 2004 tarihinde erişildi.

Hoadley, C., \& Pea, R. (2001). Finding the ties that bind: Tools in support of a knowledge-building community. In K. A. Renninger \& W. Shumar (Eds), Building virtual communities: Learning and change in cyberspace (pp.321-354). New York: Cambridge University Press. 
Jehng, J. J. (1997). The psycho-social processes and cognitive effects of peer-based collaborative interactions with computers. Journal of Educational Computing Research, 17(1), 19-46.

Kim, K. J., \& Bonk, C. J. (2002). Cross-cultural comparisons of online collaboration among pre-service teachers in Finland, Korea, and the United States. Journal of Computer-Mediated Communication, 8(1).

[Online]:http://www.ascusc.org/jcmc/vol8/issue1/kimandbonk.html adresinden 20 Temmuz 2004 tarihinde erişildi.

Kocayörük, A. (2000). İlköğretim Öğrencilerinin Sosyal Becerilerini Geliştirmede Dramanın Etkisi. Yayınlanmamış Yüksek Lisans Tezi, Ankara Üniversitesi, Sosyal Bilimler Enstitüsü, Ankara.

Komis, V., Avouris, N., \& Fidas, C. (2002). Computer-supported collaborative concept mapping: Study of synchronous peer interaction. Education and Information Technologies, 7(2), 169-188.

Kreijins, K., Kirschner, P., \& Jochems, W. (2002). The sociability of computer-supported collaborative learning environments. Educational Technology \& Society 5(1) 8-22.

Kreijins, K., Kirschner, P., \& Jochems, W. (2003). Identifying the pitfalls for social interaction in computer-supported collaborative learning environments: A review of the research. Computers in Human Behavior, 19, 335-353.

Lea, M., Rogers, P., \& Postmes, T. (2002). SIDE-VIEW: Evaluation of a system to develop team players and improve productivity in Internet collaborative learning groups. British Journal of Educational Technology, 33(1), 53-63.

Lingnau, A., Hoppe H. U., \& Mannhaupt, G. (2003). Computer supported collaborative writing in an early learning classroom. Journal of Computer Assisted Learning, 19, 186-194.

Lipponen, L., \& Hakkarainen, K. (2001). Developing culture of inquiry in computer-supported collaborative learning. Educational Technology Project of Helsinki, Helsinki 2001 Project. [Online]:www.oise.utoronto.ca/cscl/papers/lasse.pdf adresinden 23 Ağustos 2004 tarihinde erişildi.

Motteram, G. (2001). The role of synchronous communication in fully distance education. Australian Journal of Educational Technology, 17(2), 131-149. 
Northrup, P. (2001). A framework for designing interactivity in web-based instruction. Educational Technology, 41(2), 31-39.

Scardamalia, M., \& Bereite, R. C. (1996). Computer-supported intentional learning environments. [Online]: http://www.ed.gov/pubs/ EdReformStudies/EdTech/csile.html adresinden 20 Temmuz 2004 tarihinde erişildi.

Scott, S. D., Mandryk, R. L., \& Inkpen, K. M. (2003). Understanding children's collaborative interactions in shared environments. Journal of Computer Assisted Learning, 19, 220-228.

Sharda, R., Romano Jr, N. C., Lucca, J. A., Weiser, M., Scheets, G., Chung, J-M., \& Sleezer, C. M. (2004). Foundation for the study of computer supported collaborative learning requiring immersive presence. Journal of Management Information Systems, 20(4), 31-63.

Stahl, G. (2003). Building collaborative knowing: Elements of a social theory of CSCL. In J.W. Strijbos, P. Kirschner \& R. Martens (Eds.), What we know about CSCL in higher education (pp.53-86). Amsterdam, NL: Kluwer.

Svensson, L., \& Magnusson, M. (2002). Crowds, crews, teams and peers: A study of collaborative work in learning-centre based distance education. [Online]: $\quad$ www.usq.edu.au/electpub/e-jist/docs/Vol6_No1/pdf/ Svensson_Final.pdf adresinden 19 Şubat 2005 tarihinde erişildi.

Tao, P. K., \& Gunstone, R. F. (1999). Conceptual change in science through collaborative learning at the computer. International Science Education, 21(1), 39-57.

Thomas, P., \& Carswell, L. (2000). Learning through collaboration in a distributed education environment. Educational Technology \& Society 3(3). [Online]: http://ifets.ieee.org/periodical/vol_3_2000/d12.html adresinden 31 Ekim 2004 tarihinde erişildi.

Wegerif, R. (1998). The social dimension of asynchronous learning networks. Journal of Asynchronous Learning Networks, 2(1).

[Online]: http://www.aln.org/publications/jaln/v2n1/v2n1_wegerif.asp adresinden 24 Ekim 2004 tarihinde erişildi.

Whitelock, D., \& Scanlon, E. (1998). The roles of gaze, gesture and gender in cscl. Journal of Computer Assisted Learning, 14, 158-165. 
Whitelock, D., \& Scanlon, E., \& Taylor, J. (1996). Investigating the influence of audio communications technology on computer supported collaborative learning. Association for Learning Technology Journal, $4(1), 77-84$.

Yamaguchi, R., Bos, N., \& Olson, J. (2002). Emergent leadership in small groups using computer-mediated communication. In G. Stahl (Ed.), Computer support for collaborative learning: Foundations for a cscl community (pp.138-143). Hillsdale, New Jersey: Lawrence Erlbaum. 